KATHOLIEKE UNIVERSITEIT
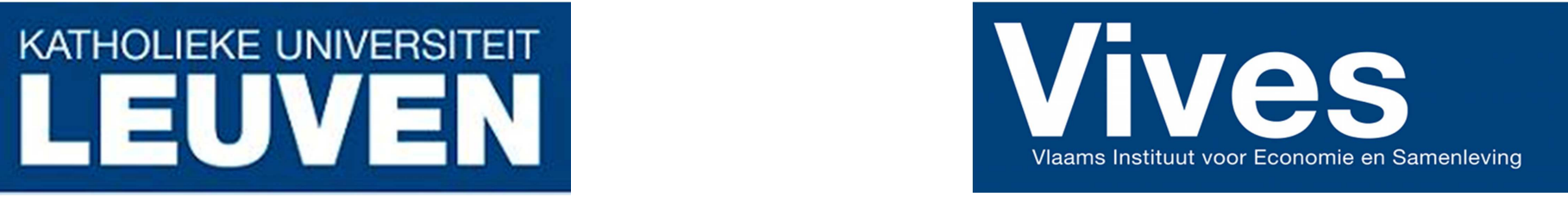

Naamsestraat 61 - bus 3550

B-3000 Leuven - BELGIUM

Tel : 32-16-326661

vives@econ.kuleuven.be

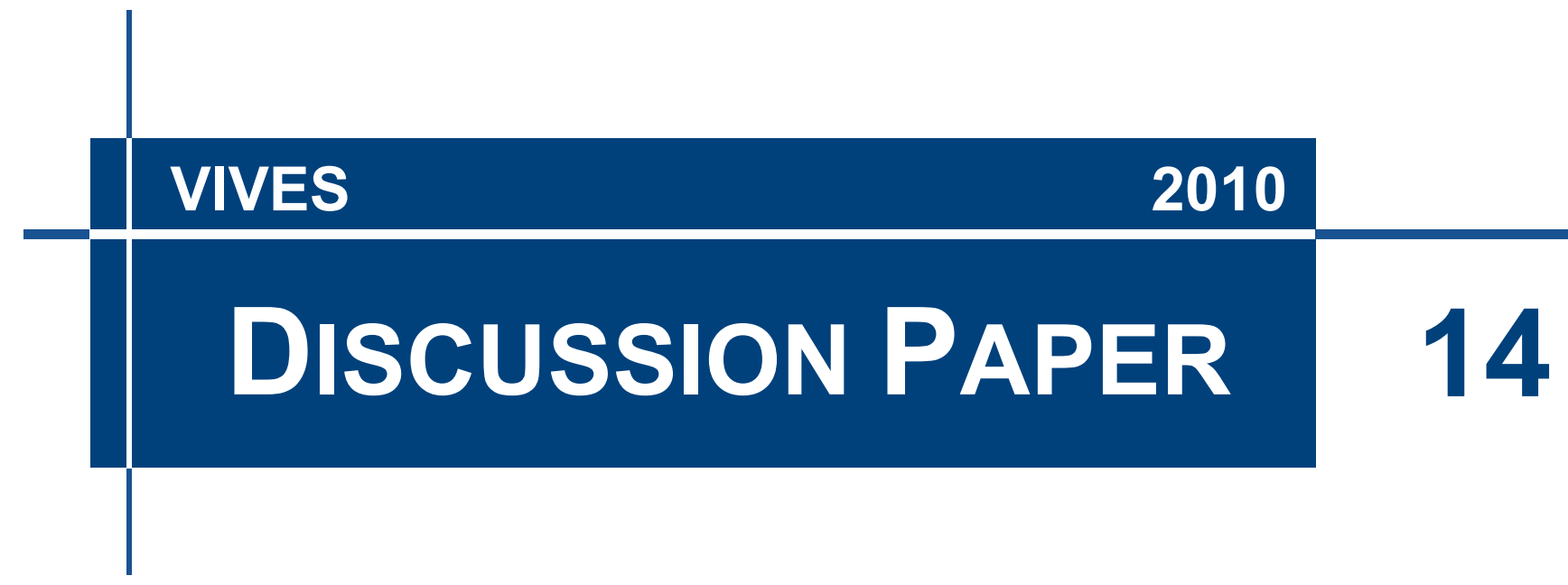

\title{
Does firm agglomeration drive product innovation and renewal?
}

Filip DE BEULE \& Ilke VAN BEVEREN

Copyright (C) 2010 by K.U.LEUVEN, VIVES. Discussion papers are in draft form. This discussion paper is distributed for purposes of comment and discussion only. It may not be reproduced without permission of the copyright holder. 


\section{Non-Technical Summary}

This paper uses data from the Community Innovation Survey for Belgium to evaluate to what extent regional concentration (clusters) of firms, also known as agglomeration economies, may be enhancing for innovation. These agglomeration economies are positive externalities that benefit firms in various ways. For innovative performance, especially externalities related to knowledge spillovers matter. Knowledge spillovers or learning externalities typically emerge between firms that belong to the same industry, often through worker mobility between firms carrying along job specific knowledge and expertise. But it can also occur through technological transfers, sharing of common technology platforms and imitation strategies of firms operating in the same sector.

This paper uses data of more than 3000 firms with detailed information on R\&D intensity, product innovation, firm size and other characteristics to show that agglomeration economies or regional knowledge spillovers matter for firm level innovation. Controlling for research and development intensity, export intensity, foreign ownership, size, region-specific effects such as urbanization economies and heterogeneity across sectors; localization economies as measured by employment concentration are shown to be a serious conduit in the innovation and renewal process of firms" product portfolio. On the other hand, firms also enjoy a significantly positive impact from regional agglomeration in the form of urbanization economies, particularly in Flanders.

These findings have implications both for firms and for policymakers. For firms in regionally clustered sectors, this means that their research and development is put to better use. The return on investment in innovation -that is expenditure on research and development- is more productive in relatively more clustered sectors. These regions accumulate sources of spillovers, which in turn attract and support innovators. This adds a regional dimension to the cumulative nature of the innovation process, and this has implications for the balance between regional and national industrial R\&D policy.

For policymakers, this implies that clustering can be an important channel in the overall promotion of innovation. Funding, however, is currently more awarded to firms in less-clustered sectors. Although it is encouraging to see that $\mathrm{R} \& \mathrm{D}$ funding has a significantly positive effect on product innovation and renewal, the results show that funding could be used more effectively and efficiently in more clustered industries. The Walloon region, in particular, could reduce its significantly lower product innovation and renewal by linking its current cluster policy with its innovation funding. As such, they could get more innovation output with less R\&D input and try to overcome their regional urbanization disadvantage. 


\title{
Does firm agglomeration drive product innovation and renewal?
}

\author{
Filip DE BEULE ${ }^{\mathrm{a}, \mathrm{b}} \&$ Ilke VAN BEVEREN ${ }^{\mathrm{a}, \mathrm{b}, \mathrm{c}}$ \\ ${ }^{a}$ Lessius University College, Department of Business Studies, Antwerp. \\ ${ }^{\mathrm{b}}$ KU Leuven, LICOS - Centre for Institutions and Economic Performance \\ ${ }^{\mathrm{c}}$ KU Leuven, VIVES - Centre for Regional Economic Policy \\ E-mail: filip.debeule@lessius.eu ; ilke.vanbeveren@lessius.eu .
}

\begin{abstract}
This paper uses data from the Community Innovation Survey for Belgium to evaluate to what extent firms located in sectors and regions characterized by high employment concentration (clusters) innovate more. We analyze the innovative performance of Belgian firms in the year 2004 and relate it to own-sector employment concentration, as well as to a number of control variables. Our findings show a positive impact of own-sector employment concentration on firm-level innovation output, lending support to the hypothesis that firms can benefit from their location within a cluster. This finding only holds for low-tech sectors and not for high-tech sectors, suggesting that congestion and competition effects have overcome localization economies, in particular for the mediumhigh-tech industries in Belgium.
\end{abstract}

JEL classification: D21, F23, 031, O33

Keywords: Product innovation, Clusters, Community Innovation Survey, Employment concentration, Agglomeration

\footnotetext{
* We are especially grateful to Manu Monard, Peter Teirlinck and the CFS/STAT Commission of the Belgian Science Policy for allowing access to the Community Innovation Survey data at the firm level for Belgium; for answering questions related to the data and for their hospitality. We would also like to thank two anonymous referees of EIBA and three anonymous referees of this journal. We are thankful to the National Social Security Office (NSSO) and VIVES (KU Leuven) for granting us access to the regional employment data by sector of activity. This paper has benefited from comments made by participants at EIBA 2008 and the Conference of the Flemish Economic Association 2008. Any remaining errors are naturally our own.
} 


\section{Introduction}

The liberalization of markets, more outward-looking development policies, and the attractiveness of regional economic integration initiatives have all contributed to push out the territorial boundaries of firms. The ease with which firms can transfer tangible and especially intangible assets across borders is being constrained by the fact that the location of the creative activities and use of these assets is becoming increasingly influenced by the presence of immobile clusters of complementary value-added activities. Thus, while globalization suggests that the location and ownership of production is becoming geographically more dispersed, other economic forces are stimulating a more pronounced geographical concentration of economic activity both within particular regions and countries (DUNNING, 1998).

Clusters have been defined as a geographic concentration of interconnected companies and institutions in a particular field (PORTER, 1998), a large group of firms in related industries at a particular location (SWANN et al., 1998) or a spatial and sectoral concentration of firms (BRESNAHAN et al., 2001). Silicon Valley (SAXENIAN, 1990) and Hollywood (CHRISTOPHERSON and STORPER, 1986) may be the world's best-known clusters, but examples abound in every international, national, regional, state and even metropolitan economy (PORTER, 1998). While this is particularly true in the more advanced nations (PORTER, 1998), some developing countries, such as several countries in South America and the Caribbean, China and India, have also taken this to heart (see for instance DE BEULE, VAN DEN BULCKE and $\mathrm{XU}, 2005)$.

While the observation that firms tend to cluster in particular regions is hardly novel (MARSHALL, 1890), it has recently been taken up to explain the stickiness of certain locations in an increasingly slippery world (MARKUSEN, 1996). These theories suggest that firms may be drawn to the same locations because proximity generates positive externalities or agglomeration effects (MARKUSEN, 1994). Economists have proposed agglomeration effects in the form of both static (pecuniary) and dynamic (technological) externalities to explain industry localization (BAPTISTA, 1998). Increasingly, the analysis of geographically clustered firms has tended to shift towards the study of predominantly untraded exchanges of knowledge and ideas (STORPER, 1995; MASKELL, 2001). Firms secure competitive advantages by gaining rapid access to knowledge concerning the innovations, techniques and strategies of competing firms (HENRY and PINCH, 2006). For these reasons, location may enhance the generation of innovation and yield higher rates of technological advance (KRUGMAN, 1991).

This paper intends to add to this strand of research by analyzing the innovation propensity of firms in Belgium. It thereby specifically investigates to what extent clustering, as measured by the relative employment concentration in a sector and region, acts as a driver of innovation. 
The current analysis is most closely related to that of BAPTISTA and SWAN (1998) and BEAUDRY and BRESCHI (2003), who use data on the United Kingdom (UK) and Italy respectively to empirically investigate the impact of employment clusters on firms' innovative output. However, the present analysis differs from the previous two papers in a number of important respects.

First, while both BAPTISTA and SWANN (1998) and BEAUDRY and BRESCHI (2003) use patent data to measure innovative output, the present analysis uses two alternative measures of innovative output, specifically a binary variable -product innovation- indicating whether firms have introduced product innovations or not, and a censored variable -product renewalmeasuring the percentage of newly innovated products in turnover. Product renewal adds to the richness of the analysis, as it measures the importance of creative destruction within a firm. It specifically determines the importance of newly created products in a firm's turnover. Using innovative output rather than patent data avoids potential misallocation issues ${ }^{1}$. Moreover, firms' innovativeness is not always a linearly increasing function of the number of patents it owns, since not every patent generates equal economic value. As such, a more direct measure of innovative output, as will be applied in the empirical analysis here, should be preferred.

Second, BAPTISTA and SWANN (1998) and BEAUDRY and BRESCHI (2003) apply their analysis only to manufacturing firms. The richness of the database employed here allows us to present results for both manufacturing and service sectors. Taking into account that services account for the majority of economic activity in Belgium, this is clearly relevant. More importantly, the data allow to investigate potential differences between high-, medium- and lowtech manufacturing and service sectors. This study is primarily concerned with firms that may be defined as being particularly innovative and tries to determine the role of clustering in product innovation and renewal regardless of the technological intensity of the sector. Instead of looking at the level of technological prowess of the industries, we focus on the innovativeness of the respective firms, and try to determine the role of localization economies in their propensity to innovate.

Section 2 discusses the relevant literature and draws hypotheses, while section 3 deals with the data description. Section 4 discusses the empirical model and methodology. Finally the results are discussed (section 5) and some conclusions are drawn (section 6).

\footnotetext{
${ }^{1}$ Patents tend to be filed by the parent company in company groups. This implies that some patents may be incorrectly assigned to the location of the parent, even if they have not been invented there.
} 


\section{Literature review and hypotheses}

There is a long tradition in industrial location theory and regional economics of theorizing about why new industries emerge in particular places and why, once these places have experienced take off, further expansion of the sector is likely to be drawn to the original or neighboring sites. The benefits that lead to clustering can be divided into demand and supply side (SWANN, 1993). On the demand side, firms may cluster to take advantage of strong local demand, particularly that deriving from related industries (BAPTISTA and SWANN, 1998). On the supply side, the main sources of location externalities can be traced back to MARSHALL (1890). It was by observing industry localization that he derived the concept of external economies. The external effects of agglomeration consist of various types of benefits and cost savings, obtained outside the market that may lead to increased productivity of a firm. In Marshall's seminal analysis of industrial organization, the three fundamental reasons for geographical concentration or spatial clustering of production were identified as the existence of a pooled market for workers with specialized skills; the provision of specialized inputs from suppliers and service providers; and the relatively rapid flow of business-related knowledge between firms, which result in what are now called technological spillovers.

The most frequently mentioned advantage is labor market pooling (BAPTISTA and SWANN, 1998). Geographical concentration of firms in the same or closely related industries creates a deep and diversified pool of workers, sufficient to realize a more specialized local division of labor. A second advantage has to do with the provision of related inputs. Location in an industrial center allows for the provision of traded and non-traded inputs specific to an industry in a greater variety and at a lower cost.

These agglomeration economies are said to occur when the unit costs of production of a firm are lower in the context of relatively dense agglomerations of other firms or specialized resources, such as skilled labor or infrastructure, than would be the case if the typical business were located elsewhere. KRUGMAN (1991) recapitulates earlier work in offering as sources of agglomeration economies: a local concentration of customers (or downstream firms) sufficient to permit suppliers to achieve economies of scale in production or distribution, great enough for local firms to amass sufficient demand to warrant the provision (usually by or via local governments) of specialized infrastructure, and large enough to attract a deep and diversified pool of workers sufficient to realize a more specialized local division of labor.

The third externality of agglomeration economies refers to the heightened prospect for technological learning to occur (not simply reductions in unit costs of production with a given technology) in relatively concentrated clusters compared with less dense locations. Studies on geographic location and economic performance have shown that economic and technological activities have a strong tendency to agglomerate at certain locations, giving rise to patterns of 
national and regional specialization; and, that the performance and the growth of firms depend to a large extent on the conditions of the environment in which they operate, and particularly on those in the immediate proximity (MALMBERG, SÖLVELL and ZANDER, 1996).

It has been argued that the transmission of technological knowledge works better within spatial boundaries (JAFFE, 1986; JAFFE, TRAJTENBERG and HENDERSON, 1993). To the extent that differences in innovative behavior among firms are in part attributable to properties of the local economies of which they are a part, most contemporary urban economic and geographic theory treats such dynamic growth processes in terms of the local production and diffusion of information relevant to the firm's decision to adopt (take up) a technology, and of the organizational capacity of that firm to make use of such information.

Clusters provide a fertile ground for learning, experimentation, and innovation due to short distances, short information time lags, and relatively inexpensive communication (VON ZEDTWITZ and HEIMANN, 2006). And, although firms in clusters densely populated by other innovative firms positively affect the likelihood of innovating, quite strong disadvantages seem to arise from the presence of non-innovative firms in a firm's own industrial sector (BEAUDRY and BRESCHI, 2003), firms have been found to be considerably more likely to innovate if sectors are clustered (BAPTISTA and SWANN, 1998).

All of these factors are covered by the notion of agglomeration, which suggests that the stickiness of a place resides not in the individual firms or workers, but in the external economies available to each firm from its spatial conjunction with other firms and suppliers of services at a particular location. A further distinction in agglomeration economies is made between urbanization and localization economies. The difference between these two cases is that, if the agglomeration benefits accrue to activities in the same sector located at the same place these are termed localization economies, whereas, if the benefits accrue to a diverse range of local sectors, they are termed urbanization economies. Localization economies stand for the externalities of own sector concentration, while urbanization externalities denote the effect of the size and heterogeneity of an agglomeration. As testable hypotheses, it follows that agglomerations with more sector concentration will demonstrate more innovation than sectors with less agglomeration; and/or that regions with larger size and diversity ought to, ceteris paribus, enjoy higher innovation rates than regions with a smaller and more homogenous population of firms.

Hypothesis la. Firms in sectors with higher agglomeration will have more product innovation and renewal, ceteris paribus, than firms in sectors with lower agglomeration. 
Hypothesis 1b. Firms in regions with higher agglomeration will have more product innovation and renewal, ceteris paribus, than firms in regions with lower agglomeration.

There is a widespread belief that the high-tech industries are primarily the growing and thriving industries of tomorrow for high-income economies. The dominant view is that such high-tech industries hold the key to the future, whereas the low- and medium-tech sectors are usually regarded as based on low levels of knowledge and without any real future in many industrialized economies. Low-tech industries are sometimes even called sunset industries, indicating that these industries are seen as declining and relocating to emerging economies, and eventually perhaps even vanishing from Western countries (CHRISTENSEN, 2010). In a similar vein, only the high-tech sectors supposedly offer prospects for development, and therefore it makes sense that research should focus on these sectors and that policymakers should favor them.

In Europe, for instance, policy was driven by the Lisbon Agenda since 2000, which intended to make the EU the most competitive, knowledge-based economy in the world. The initial Lisbon Agenda had a large number of goals, in both quantified and qualified measures, in different areas. In 2005, the results that so far had been reached were evaluated in mid-term reviews. Due to the disappointing results, the Lisbon Agenda was forced to change some of the implementation processes. The many quantitative goals were reduced, but the goal to dedicate three percent of GDP to R\&D was kept. The member states and their regions were to formulate reform programs, and use these as their main instrument in order to reach the goals. This clearly diverted policy towards R\&D-intensive high-tech sectors. Although the new and much-improved Europe 2020 economic strategy now specifically promotes innovation and creativity, it still includes the three per cent investment rate in research and development.

Innovative industrial sectors have therefore almost invariably been inferred as those clusters whose sectoral specialization is in high-tech industries. Several studies have made cross industry comparisons and have found a high degree of spatial clustering in particular industries that face high technological opportunity (FELDMAN, 1999). AUDRETSCH and FELDMAN (1996) find a direct relationship between the propensity for industries to concentrate geographically and the knowledge intensity of the industry's activity. Similarly, HENDERSON (1994) finds that both localization and urbanization effects are most important for high-tech industries. However, ALECKE, ALSLEBEN, SCHARR and UNTIEDT (2006) find no general relationship between agglomeration and high-technology related business among German manufacturing industries which means that simply being high-tech does not make an industry agglomerate, nor realize greater innovative productivity. 
Furthermore, in spite of this widespread view, high-tech industries (high-tech manufacturing as well as high-tech services) only provide a marginal contribution to Western economies (VON TUNZELMANN and ACHA, 2005; HIRSCH-KREINSEN, 2008a, 2008b). Quantitatively between $90 \%$ and $97 \%$ of GDP is accounted for by low- and medium-tech sectors in Western European countries (HIRSCH-KREINSEN et al., 2003). Despite a perception of the opposite, the relative share has only increased marginally. In Belgium too the high-tech manufacturing and service industries together provide approximately five per cent of total employment or net value added (DE BEULE and VAN BEVEREN, 2009).

Besides, clustering (or spatial concentration of industries) is a far more common pattern for traditional industries than for high-tech industries (KRUGMAN, 1991). Industrial or service clusters can exist without being particularly based on high-technology (ASHEIM, COOKE and MARTIN, 2006). Moreover, the literature demonstrates that innovations are not confined to firms in high-tech industries (VON TUNZELMANN and ACHA, 2005; HIRSCH-KREINSEN, 2008a, 2008b). Rather, firms in low-tech industries often rely on innovations, not only in the form of new processes but also by developing new products (CHRISTENSEN, 2010).

There is a small yet growing body of literature that criticize the overemphasis that both economic analyses and policies often put on high-tech industries. The generation, diffusion and utilization of knowledge has become a core characteristic of firms and economic activity as a whole. Not only high-tech but also traditional sectors have also undergone change (CHRISTENSEN, 2010). The result is that many mature, low-tech, allegedly threatened industries are not only still located in their industrialized home countries; they continue to contribute the lion's share of employment and value-added (DE BEULE and VAN BEVEREN, 2009).

If local industry agglomeration increases innovation by providing industry specific complementary assets and activities that may either lower the cost of suppliers to the firm or create greater specialization in input and output markets, one would expect that industries in which complementary assets are more important would be more likely to realize greater innovative productivity as a result. Similarly, industries in which knowledge spillovers are more prevalent have a greater propensity for innovative activity to cluster than industries where knowledge externalities are less important (AUDRETSCH and FELDMAN, 1996). The limits to the positive process by which clusters are self-reinforced are related to congestion and competition effects that arise from input and output markets. One would expect that, as the cluster grows, congestion effects eventually overcome the benefits. Given that it is difficult to predict in which sectors agglomeration effects would outweigh the congestion effects, both hypotheses are put forward.

Hypothesis 2a. $\quad$ Firms in high-tech sectors will benefit from localization economies in their product innovation and renewal, ceteris paribus. 
Hypothesis 2b. Firms in low-tech clusters will benefit from localization economies in their product innovation and renewal, ceteris paribus.

\section{Data}

This paper combines data from several data sources. First, we rely on Belgian employment data by region and sector, provided by National Social Security Office (NSSO, 2009); and European employment data at the sector level, obtained from EUROSTAT (2009). These data will be used to calculate a measure of relative employment concentration, which will be our central variable of interest, i.e. it is assumed to represent the potential for clustering at the regional and sector level. We combine this data set with firm-level data from the Community Innovation Survey (CIS) for Belgium, obtained from BELSPO (2006). The CIS data provide information on firms' innovative behavior, as well as on a number of other firm characteristics, such as foreign ownership, firm size and sector of activity. In what follows, we will discuss each of these data sources in turn, after which we will summarize the characteristics of the combined data set. Our final data set combines information on firm-level innovative output, R\&D activities and other firm-level characteristics with data on employment concentration, defined at the level of each region and sector.

The NSSO database contains detailed information on the number of plants and employees for each sector and region in Belgium. Since every employer in Belgium is legally required to report employment data to the NSSO, the coverage of the database is close to a hundred percent. To identify clusters, we follow the definition of the EUROPEAN CLUSTER OBSERVATORY (2010) and calculate a relative specialization measure (cluster variable) which compares employment concentration in a particular region and sector to employment concentration defined at the European Union (EU) level. We believe that the EU15-level is the relevant level to define our measure of relative employment concentration, given the small size of the Belgian economy combined with the single market created within the Euro zone.

Intuitively, the cluster variable measures, for a particular sector and region, to what extent it has been able to attract more firms and workers compared to other EU regions. High own-industry employment concentration thus acts as a proxy for the potential for intra-industry spillovers and linkages. While the EUROPEAN CLUSTER OBSERVATORY (2010) considers sectors as clusters in a particular region if their specialization quotient is at least 2 , we chose not to impose this cut-off in the data. Specifically, we will include a continuous measure of employment concentration in our empirical analysis, rather than assigning a dummy to all sectors with relative employment concentration higher than 2 . This should allow for a more flexible specification. 
Formally, our cluster variable is defined as follows:

$$
\text { Cluster }_{j r}=\frac{E m p_{j r} / E m p_{r}}{E m p_{j, \text { eur }} / E m p_{\text {eur }}}
$$

Where Emp refers to employment, $r$ to a NUTS1-region, $j$ to a particular two-digit NACE sector and eur refers to the EU-15 region.

Data on European employment by sector were obtained from EUROSTAT (2009). Clusters are defined for relatively aggregated regions and sectors. Specifically, there are 60 NACE 2-digit sectors in the NACE Rev. 1.1 classification. Moreover, at the NUTS1-level, there are three regions in Belgium: the Flemish region (North), the Walloon region (South) and Brussels (centre). The motivation for this choice is twofold. First, innovation and cluster policy are defined at the regional (NUTS1-level) in Belgium, i.e. these policy decisions are regionalized, implying that the three regions can determine their cluster (and innovation) policies autonomously. Hence, defining employment concentration in this way allows us to evaluate to what extent policy initiatives undertaken by the regional governments to stimulate positive agglomeration effects have been successful, particularly with respect to the innovative performance of the firms that are part of those regions.

Second, the Community Innovation Survey data, which will be discussed in further detail below, is representative for the population of firms employing at least ten employees, at the two-digit NACE sector level and NUTS1 regional level. Hence, by defining relative employment concentration at this level, we ensure representativeness of firms in the sample across sectors and regions used to define our employment concentration measure.

To identify the impact of own-sector employment concentration on firms' innovative performance, we merge the employment concentration data with firm-level data on innovation and other variables included in the Community Innovation Survey database for Belgium (CIS4), obtained from BELSPO $(2006)^{2}$. The survey collects information on innovations at the firm level for the period 2002 - 2004. Although the survey is organized by the EU, data are collected by national authorities and firm-level data can only be obtained on a national basis. For Belgium BELSPO is responsible for the data collection. Apart from innovation-related information, the survey also records detailed information on employment, turnover, ownership and exports of the firm. Although the CIS4-questionnaire pertains to the years 2002-2004, quantitative data are only available for 2004 . Hence, the data are cross-sectional in nature.

\footnotetext{
${ }^{2}$ We would like to thank Manu Monard, Peter Teirlinck and the CFS-STAT Commission of the Belgian Science Policy for granting access to the data at the offices of the Belgian Science Policy in Brussels.
} 
The CIS data are available for 3,322 firms. The data are stratified by region (NUTS1), sector (NACE 2digit) and size class. This implies that if a higher proportion of survey responses are obtained from a particular region (sector) compared to its proportion in the population, additional survey responses will be collected in the other regions (sectors) until the sample and population proportions match. Hence, the CIS data are representative for the full population of Belgian firms employing at least 10 people $^{3}$.

The data were checked for outliers, which were omitted, as where firms that have missing information on some of the key variables. Hence, the final sample consists of 3,246 firms. The questionnaire contains detailed information on firms' innovation activities. Apart from R\&D expenditures, which are reported for 2004; the data set contains information on whether firms have introduced product and/or process innovations during 2002-2004 as well as on the share of turnover that is accounted for by the introduction of new products in 2004 (either new to the market or new to the firm). Appendix B provides an overview of the specific questions (relevant to the current analysis) asked to firms in the questionnaire concerning their innovation activities.

While research spending of firms can be considered a reasonable proxy of firm-level innovative output in the absence of information on the actual innovations firms have introduced, there are several drawbacks associated with the use of R\&D spending, which is essentially an input in the innovation production function (see for instance MAIRESSE and MOHNEN, 2002 and Section 4 ), as a measure of firm-level innovation. First, not all innovation efforts actually lead to the introduction of product or process innovations, i.e. it is possible that firms' efforts to innovate fail for some reason, in which case using $R \& D$ rather than actual innovations leads to an overestimation of firms' innovative activities. Second, it is not unlikely that there is a considerable time lag between firms' investment in R\&D and the actual introduction of an innovation to the market, in which case the timing of the R\&D and innovation decisions do not match, leading to an overestimation of innovation in some years and an underestimation in later years, when the level of $R \& D$ spending is lower and innovative output is higher.

Similarly, the use of patent data (which can be considered as a true innovation output measure) has been criticized in recent years (see for instance SMITH, 2005), primarily because not all inventions are patented, patents can differ greatly in their economic impact and the propensity to patent is highly variable across industries and also across firm sizes.

The drawbacks associated with the use of more traditional innovation measures (R\&D and patents) has led to an increasing reliance on other firm-level innovation measures in empirical work in recent years. While some of these works use other data sources than the CIS data (e.g. BAPTISTA and SWAN, 1998; CALDERA, 2010; CASSIMAN, GOLOVKO and MARTINEZ-

\footnotetext{
${ }^{3}$ For a detailed overview of the CIS population selection process and the sampling issues involved, we refer to TEIRLINCK (2005).
} 
ROS, 2010), many recent papers using European data use the CIS data, examples include CASSIMAN and VEUGELERS (2002), CRISCUOLO et al. (2010), DAMIJAN et al. (2008) and VAN BEVEREN and VANDENBUSSCHE (2010).

In spite of the advantages associated with the use of direct innovation output measures, such as the share of new products in firm turnover, rather than input measures like R\&D intensity or indirect measures like patents; it should be noted that the CIS data are collected using a survey and are thus potentially subject to self-perception of the firm ${ }^{4}$. This is particularly true for the output measures (innovation dummies and the share of new products in turnover), since these are measures that are not generally recorded in firms' accounting records (unlike R\&D expenses) (SMITH, 2005).

We merge the data obtained from the NSSO database on employment concentration with the CIS data in order to identify the impact of own-sector employment concentration within each of the three Belgian regions (clustering) on firm-level innovation. Table 1 summarizes the key variables for each of the three Belgian regions considered. As can be seen in the first line of Table 1, the Flemish region is the largest region with 1,525 firms, followed by the Walloon and Brussels region with 1,007 and 714 firms respectively. As already noted above, the regional distribution of the CIS data is representative for the population of Belgian firms employing more than 10 employees.

All values reported in Table 1, with the exception of the first row, are sample means. The innovation characteristics reported suggest that the Flemish region is the most innovative region of the three. While it has the same average R\&D intensity compared to the Walloon region, it has the highest reported proportion of product innovation of the three regions. Specifically, almost 37 percent of all Flemish firms report having introduced a product innovation between 2002 and 2004, compared to 24 percent in the Walloon region and 22 percent in Brussels. Similarly, Flemish firms have an average share of new products in turnover amounting to almost 9 percent of turnover, compared to 6 percent in Brussels and 5 percent in the Walloon region. In the Flemish and Walloon region, about 14 percent of all firms report having received funding from local, national or EU governments.

In terms of other firm characteristics, such as firm size, export intensity and employment concentration, firms located in the Flemish and Walloon region are very similar on average, while firms located in Brussels are on average more likely to be foreign-owned (34 percent foreign ownership compared to 24 percent for the other two regions) and they tend to export less (14 percent of their turnover, compared to about 26 percent in the other two regions).

\footnotetext{
${ }^{4} \mathrm{We}$ are thankful to an anonymous referee for pointing this out.
} 
Not surprisingly, employment concentration is on average highest in Brussels, which is the smallest region with the highest population density. In the empirical model below, we will take these regional differences into account by accounting for firm size, export intensity and foreign ownership in the regression framework, in addition to the firm-level innovation inputs and our cluster (employment concentration) variable (cfr. Hypothesis 1a). Additionally, to control for urbanization economies (cfr. Hypothesis 1b), which are specific to the region considered, we will include region dummies in the analysis. Finally, we include sector dummies to control for sector heterogeneity.

\section{Empirical model}

To gain further insights on the link between clustering and the innovative behavior of firms, we estimate an empirical model using two different dependent variables: (i) firm-level product innovation, a dummy variable indicating whether the firm has introduced a product innovation between 2002 and 2004; and (ii) product renewal, defined as the share of new products in turnover. The data are cross-sectional in nature and pertain to the year 2004.

To formally test to what extent localization economies have a positive influence on firm-level product innovation and renewal (Hypothesis 1a), we include a cluster variable, defined in the previous section as relative employment concentration in each two-digit NACE sector and NUTS1-region, as an independent variable in both regressions. Furthermore, to control for potential urbanization economies, which are specific to each of the regions considered, we include NUTS1-level region dummies in both specifications (Hypothesis 1b).

Our basic estimation framework relies on the model of MAIRESSE and MOHNEN (2002), who view firm-level innovative output as a function of its innovative inputs ( $\&$ D effort) as well as a number of other determinants.

MAIRESSE and MOHNEN (2002) apply their framework to micro-aggregated data for seven EU countries from the first Community Innovation Survey (CIS). They decompose firm-level innovative output differences for each country over time into differences in R\&D effort and differences in a number of other firm-and industry-level determinants of innovation using a framework that draws on the traditional production function literature. Their results suggest that differences in innovative inputs ( $R \& D$ activities) account for a sizeable share of the differences in innovative output.

Similarly, CRISCUOLO et al. (2010) compare innovation processes to traditional production processes and relate innovative output to innovative inputs in what they call an "innovation 
production function". Rather than calculating the contribution of different effects using a decomposition as in MAIRESSE and MOHNEN (2002), they apply their model in a regression context to a sample of UK firms, using two consecutive waves of the CIS data. The dependent variables are four innovation output variables (innovation dummy, share of new products in sales, patent protection dummy and number of patents) and the independent variables include an innovation input measure ( $R \& D$ personnel or an $R \& D$ dummy) and a number of control variables. Their results suggest a significantly positive impact of firm-level innovative effort on its product innovation and product renewal behavior.

Moreover, as argued by TALLMAN et al. (2004), investment in R\&D activities additionally acts as a firm-level measure of absorptive capacity, since it (indirectly) facilitates knowledge transfers from other firms. We therefore expect a positive impact of firm-level R\&D intensity on its propensity to introduce a product innovation and on its product renewal.

To account for firms' innovative effort in our framework, we include firm-level R\&D-intensity, defined as total internal R\&D efforts over sales in 2004, as an independent variable in the model. Based on the above, we expect to find a positive and significant impact of firms' innovative inputs (measured as the ratio of R\&D expenses over sales) on firm-level innovative output.

Access to finance, particularly in the context of uncertain innovation outcomes, may also affect firms' ability to innovate, and particularly the commercialization of their innovations as measured by their innovative sales intensity (see for instance AHARANSON, BAUM and PLUNKET, 2008). We therefore include a funding dummy in the empirical model, indicating whether the firm had acquired innovation subsidies from regional, national or EU authorities.

Apart from these R\&D-related input measures, we include a number of additional control variables. As is common in the literature (see for instance BAPTISTA and SWANN, 1998; and CRISCUOLO et al., 2010), we control for heterogeneity across sectors by including sector dummies in all regressions. Additionally, we control for firm size, proxied by the total number of full-time equivalent employees at the firm level.

Following the recent literature investigating the relationship between firm-level exports and innovation (see for instance AW, ROBERTS and WINSTON, 2007; BECKER and EGGER, 2007; CALDERA, 2010; CASSIMAN et al., 2010 and DAMIJAN, KOSTEVC and POLANEC, 2008), our model additionally includes firm-level export intensity as a control variable. One of the main issues raised in this literature is the question of causality, i.e. does exporting drive firmlevel innovative effort (R\&D) and/or output (product and process innovation) or does innovation drive exporting. 
While results from this literature tend to be mixed and sensitive to the data and empirical specifications used, results by DAMIJAN et al. (2008) suggest that after accounting for potential endogeneity of firm-level export and innovation decisions, that the causality runs from exporting to innovation and not vice versa. Moreover, results of VAN BEVEREN and VANDENBUSSCHE (2010), specifically for Belgium and using the same data used in the present paper, similarly suggest that the causality runs from exporting to innovation, once endogeneity issues are taken into account.

Finally, the empirical model includes a dummy variable controlling for the ownership status of the firm. The inclusion of this variable in the model is driven both by the specifics of the Belgian data and the available empirical literature. Belgium is a small open economy, characterized by a relatively high dependence on foreign subsidiaries on multinational firms, both in terms of employment and output generation (see for instance DE BEULE and VAN BEVEREN, 2009) and innovation (TEIRLINCK, 2005). Specifically, in our sample, foreign firms account for about a quarter of all firms (26 percent), 43 percent of total employment generated in 2004 and 54 percent of total turnover. In terms of innovative effort and output, foreign firms account for about 52 percent of total R\&D spending in the sample and 67 percent of total turnover attributed to new products (product renewal).

Moreover, results by CRISCUOLO et al. (2010) and Castellani and Zanfei (2006), who investigate the relationship between the global engagement status of the firm and its innovative output using CIS data for the UK and Italy respectively, suggest that the foreign ownership status of the firm is positively related to its propensity to innovate, as well as to its product renewal (measured as the share of new products in sales).

In summary, our full empirical model looks as follows:

$$
\begin{aligned}
\text { Inn }_{i}= & \alpha_{0}+\alpha_{1} \text { Cluster }_{j r}+\sum_{r} \beta_{r} \text { Region }_{r}+\alpha_{2} \text { RD }_{i}+\alpha_{3} \text { Funding }_{i}+\alpha_{4} \text { Exp }_{i} \\
& +\alpha_{5} \ln \text { Emp }_{i}+\alpha_{6} \text { Foreign }_{i}+\sum_{j} \gamma_{j} \text { Ind }_{j}
\end{aligned}
$$

where

$I_{i} n_{i} \quad$ Firm-level innovation measure, defined as product innovation (dummy), or the share of new products in turnover (censored variable).

Cluster $_{i} \quad$ Continuous measure of employment concentration, cfr. Section 3.

Region $_{i} \quad$ Region dummy, defined using NUTS1-regions.

$R D_{i} \quad \mathrm{R} \& \mathrm{D}$-intensity of the firm, measured as total internal $\mathrm{R} \& \mathrm{D}$ expenditures relative to firm turnover.

Funding $_{i} \quad$ Funding dummy, equal to one if the firm has acquired funding from regional, national or EU authorities. 
$E m p_{i} \quad$ Employment of the firm, measured in full-time equivalents.

$\operatorname{Exp}_{i} \quad$ Firm-level export intensity, defined as the share of exports in total turnover.

Foreign $_{i} \quad$ Foreign ownership dummy, equal to one if the head office of the group is located outside of Belgium.

Ind $\quad$ Industry dummies (two-digit Nace level).

Estimation of (1) is achieved by using a different methodology that depends on the innovation measure used. Product innovation is an indicator variable, hence a logit model is estimated. The share of new products in turnover is limited below by zero and above by one, which is why a tobit model is used.

\section{Empirical Results}

The results of estimating (1) for the full sample of firms are given in tables 2 and 3. Table 2 presents results for the product innovation variable, indicating whether or not the firm has carried out a product innovation during 2002-2004; while table 3 summarizes results for product renewal defined as the share of new products in turnover of the firm in 2004. Both regressions include sector dummies, which are unreported for brevity. Reported values are marginal effects, $t$-values are given between brackets.

\section{[Table 2: Product innovation: logit regression results]}

[Table 3: Share of new products in sales: tobit regression results]

The following stepwise approach is followed in both tables, i.e. we start out from a very basic model in column (I), including only the firm-level control variables R\&D-intensity and firm size in addition to sector and region dummies. Column (II) displays results of the baseline model (I), including our cluster variable, measured by relative own-sector employment concentration, as explained in detail in Section 3. Columns (III) and (IV) additionally add the globalization measures (export intensity and foreign ownership) and the funding variable, indicating whether a firm has received funding from regional, national or EU government authorities.

Apart from the dependent variables, the two models summarized in Tables 2 and 3 are identical. We will therefore discuss the results simultaneously, focusing on their similarities and differences.

Turning to the results on the cluster variable, results in Tables 2 and 3 suggest that firms can benefit from positive localization economies to increase their innovative performance, as was hypothesized in section 2 (Hypothesis 1a). Results in both tables suggest that own-sector 
relative employment concentration has a positive and significant effect on firms' propensity to innovate and on their innovation intensity (product renewal). The magnitude of the effect is very stable across the different specifications shown in the tables and appears to be robust to the inclusion of additional control variables such as the globalization measures and the funding variable.

As was stated in Hypothesis $1 \mathrm{~b}$, it can be expected that firms do not only benefit from sectorspecific localization economies, but also from more general region-specific urbanization economies. Summary statistics shown in table 1 further showed that on average, firms in the Flemish region are more innovative (both in terms of their propensity to innovate and for their innovation intensity) compared to firms located in the other two Belgian regions. These differences might be attributable to the type of static urbanization economies described in Hypothesis $1 \mathrm{~b}$, although it should be noted that, due to their inclusion as dummy variables, they might also capture other region-specific characteristics, other than agglomeration effects.

Tables 2 and 3 report marginal effects for the region dummies for the Brussels and Walloon region (the Flemish region is the benchmark, included in the constant). For product innovation, both region dummies are significantly negative, suggesting that the Flemish region has a higher potential to benefit from static urbanization economies. For product renewal, results for the Walloon region dummy remain significantly negative throughout, but results for Brussels are less conclusive. However, to the extent that these regional dummies act as a good proxy for region-specific agglomeration potential, these results seem to lend support to hypothesis $1 \mathrm{~b}$, i.e. firms located in regions characterized by higher urbanization economies, tend to be more innovative.

As expected, firm-level innovative effort, measured as the firm's R\&D intensity, seems to act as a significant driver of both firms' propensity to innovate and their innovation intensity. This result is also in line with results reported in the empirical literature, see for instance CRISCUOLO et al. (2010), GRIFFITH et al. (2006) and DUGUET (2006). Firm size, defined as the logarithm of firm-level employment, similarly has a positive and significant effect on firms' propensity to innovate and on its innovation intensity.

For product innovation, the magnitude of the marginal effect for the cluster variable amounts to 0.007 , implying that a one percent increase in relative employment concentration increases the firms' propensity to innovate by 0.7 percentage points. Since the overall propensity to innovate in the sample amounts to 29.7 percent, an increase of 0.7 percentage points implies a rise in the probability to innovate by 2.36 percent. For product renewal, the magnitude of the cluster effect amounts to 0.002 , suggesting that a one percent increase in relative employment concentration increases firms' product renewal by 0.2 percent. These results suggest that clustering has a 
positive and significant impact both on firms' propensity to innovate and on their product renewal.

Results for the other control variables reported in Tables 2 and 3 are largely as expected. Export intensity and foreign ownership both have a positive and significant impact on firm-level innovative output. Firm-level funding further seems to act as a significant driver of firms' innovative performance.

As was noted in Section 2, there is a widespread belief that clustering benefits apply mainly to high-tech industries. This belief is further fostered by public policy makers, interested in creating the conditions that would lead to the creation of their own Silicon Vallye-type of hightechnology cluster. However, as the literature review in Section 2 indicates, evidence on the relationship between dynamic agglomeration effects and innovation tend to be mixed. Moreover, specifically for the Belgian and more generally for the European case, high-technology sectors tend to be relatively small and have a minor contribution to overall employment and output generation (DE BEULE and VAN BEVEREN, 2009).

Our data set is unique in the sense that it is representative for the sector distribution of the Belgian economy and includes firms from all sectors, both in manufacturing and services 5 . This allows us to investigate to what extent there exists heterogeneity across sectors in terms of the ability of firms to benefit from dynamic localization economies, as proxied by our relative employment concentration measure. Therefore, to investigate Hypothesis 2, we estimate the full empirical model (column IV in Tables 2 and 3) separately for high-technology and lowtechnology sectors, both in manufacturing and services. To group firms into sectors, we apply the Eurostat (2008) sector classification according to technology intensity. The breakdown of the classification can be found in Appendix Table A.1.

[Table 4: Product innovation: regression results by sector]

[Table 5: Share of new products in sales: regression results by sector]

Within the manufacturing sector, we distinguish between four types of sectors: high technology (HTM), medium-high technology (MHM), medium-low technology (MLM) and low-technology (LM). For services, we report results separately for high technology services (HTKIS) and low technology services (LTKIS). The results of these estimations are shown in Tables 4 and 5 for product innovation and product renewal as the dependent variable respectively.

\footnotetext{
${ }^{5}$ It should be noted that the CIS data only includes business sectors, i.e. all sectors ranging from the mining sector (NACE 14) to the business services sector (NACE 74). This excludes agriculture and sectors such as education and other public sectors from the data and analysis.
} 
Several interesting results emerge from Tables 5 and 6. First, R\&D-intensity does not act as a significant determinant of firm-level innovative output in all sectors, although the results are understandably better for product renewal. It does not necessarily take a huge R\&D effort to introduce one new product, but renewing your product portfolio clearly does. In particular, the marginal effect for research intensity is insignificant for medium- and low technology manufacturing sectors when product innovation is the dependent variable; while it is significant for all sectors except for high technology services when innovative sales intensity is the dependent variable. Second, results on the cluster variable suggest that only firms that are active in low technology sectors (both in manufacturing and services) are able to benefit from positive localization economies for their innovative performance. Hence, these results lend support to Hypothesis $2 b$, i.e. firms in low technology sectors experience positive agglomeration effects fostering their innovative output. Comparing the magnitude of the effects for low technology manufacturing and services, it seems that agglomeration effects play a larger role in manufacturing than in services.

Furthermore, firms in medium-high-tech sectors even have a significantly negative impact from clustering. This indicates that these sectors have reached the limits to the positive feedback process of clusters and that congestion and competition effects that arise from input and output markets have overcome the benefits. The data indicate that Belgium clearly has some specific (medium-)high-tech sectors, like pharmaceuticals and (petro)chemicals, where congestion and competition effects have overturned localization externalities.

Finally, foreign ownership is significantly positive in the medium-high-tech manufacturing as well as low-tech service sectors, but significantly negative in the high-tech sectors. This suggests that foreign subsidiaries in medium- and low-tech sectors develop new and innovative products and services, while subsidiaries in high-tech sectors have rather been set up as listening posts for the benefit of the corporate parent. Export intensity is clearly conducive to innovation for medium- and low-tech manufacturing and service sectors, while insignificant for the high-tech manufacturing sector. As the high-tech manufacturing sector is already highly international, there is still room for improvement for most other sectors. Funding has a significantly positive effect on innovativeness, while urbanization economies seem to play no significant role in the Walloon region.

\section{Recommendation}

The current analysis has shown that agglomeration can be an important catalyst in the innovation process of firms. On the one hand, firms enjoy a significantly positive impact from increased 
sectoral concentration. Controlling for research and development intensity, export intensity, foreign ownership, size, region-specific effects such as urbanization economies and heterogeneity across sectors; localization economies as measured by employment concentration are shown to be a serious conduit in the innovation and renewal process of firms' product portfolio. On the other hand, firms also enjoy a significantly positive impact from regional agglomeration in the form of urbanization economies, particularly in Flanders.

These findings have implications both for firms and for policymakers. For firms in regionally clustered sectors, this means that their research and development is put to better use. The return on investment in innovation -that is expenditure on research and development- is more productive in relatively more clustered sectors. These regions accumulate sources of spillovers, which in turn attract and support innovators. This adds a regional dimension to the cumulative nature of the innovation process, and this has implications for the balance between regional and national industrial R\&D policy.

For policymakers, this implies that clustering can be an important channel in the overall promotion of innovation. Funding, however, is currently more awarded to firms in less-clustered sectors. Although it is encouraging to see that $R \& D$ funding has a significantly positive effect on product innovation and renewal, the results show that funding could be used more effectively and efficiently in more clustered industries. The Walloon region, in particular, could reduce its significantly lower product innovation and renewal by linking its current cluster policy with its innovation funding. As such, they could get more innovation output with less R\&D input and try to overcome their regional urbanization disadvantage.

The results of the analysis with regard to the second hypotheses show that low-tech sectors benefit from localization economies in their innovation process, while (medium) high-tech sectors do not. This indicates that some sectors have reached the limits to the positive feedback process and that congestion and competition effects have overcome the benefits. This, in turn, suggests that Belgian regional innovation policy -which currently puts much hope into the fast and effective development of high-tech clusters- should not overlook the stimulus of innovation in low-tech industries, especially given its importance in terms of employment and value-added. The results indicate that policies should focus more on the innovation of low- and medium-tech industries, although perhaps not at the expense of high-tech sectors.

\section{References}

AHARONSON B. S., BAUM J. A. C. and PLUNKET A. (2008) Inventive and uninventive clusters: The case of Canadian biotechnology, Research Policy 37, 1108-31.

ALECKE, B., ALSLEBEN, C., SCHARR, F. and UNTIEDT G. (2006) Are there really high- 
tech clusters? The geographic concentration of German manufacturing industries and its determinants, The Annals of Regional Science 40, 19-42.

ASHEIM, B., COOKE, P. and MARTIN, R., (2006). Clusters and Regional Development. Critical reflections and explorations. Routledge.

AUDRETSCH D. B. and FELDMAN M. P. (1996) R\&D spillovers and the geography of innovation and production, American Economic Review 86, 630-40.

AW B. Y., ROBERTS M. J. and WINSTON T. (2007) Export market participation, investments in R\&D and worker training, and the evolution of firm productivity, The World Economy 30, 83-104.

BAPTISTA R. (1998) Clusters, innovation and growth, in SWANN P., PREVEZER M. and STOUT D. (Eds) The Dynamics of Industrial Clustering: International Comparisons in Computing and Biotechnology, pp. 13-51. Oxford University Press, Oxford.

BAPTISTA R. and SWANN P. (1998) Do firms in clusters innovate more?, Research Policy 27, 525-40.

BEAUDRY C. and BRESCHI S. (2003) Are firms in clusters really more innovative?, Economics of Innovation \& New Technology 12, 325.

BECKER, S. O., and P. EGGER (2007) Endogenous Product Versus Process Innovation and a Firm's Propensity to Export, CESIFO Working Paper Series, 1906.

BELSPO (2006) Community Innovation Survey Data Wave 4. Belgian Science Policy, Brussels.

BRESNAHAN, T., MORANT, T., and WALLSTEN, S. (2001) "Northern Virginia's High-Tech Corridor and the Economics of Regional Development", Working Paper, Stanford Institute for Economic Policy Research (SIEPR), Stanford University, Stanford CA.

CALDERA, A. (2010) Innovation and Exporting: Evidence from Spanish Manufacturing Firms, Review of World Economics Forthcoming.

CASSIMAN, B., E. GOLOVKO, and E. MARTÍNEZ-ROS (2010) Innovation, Exports and Productivity, International Journal of Industrial Organization Forthcoming.

CASSIMAN, B., and R. VEUGELERS (2002) R\&D Cooperation and Spillovers: Some Empirical Evidence from Belgium, American Economic Review 92, 1169-1184.

CASTELLANI D. and ZANFEI A. (2006) Multinational firms, innovation and productivity. Edward Elgar Publishing, Cheltenham.

CHRISTENSEN, J.L. (2010) Low-tech, high-performing clusters in knowledge-based economies, Opening Up Innovation: Strategy, Organization and Technology, Druid Summer Conference: London Business School.

CHRISTOPHERSON S. and STORPER M. (1986) The city as studio, the world as back lot: The impact of vertical disintegration on the location of the motion picture industry, Environment and Planning D: Society and Space 4, 305-20.

CRISCUOLO, C., J. E. HASKEL, and M. J. SLAUGHTER (2010) Global Engagement and the Innovation Activities of Firms, International Journal of Industrial Organization 28, 191202.

DAMIJAN, J. P., C. KOSTEVC, and S. POLANEC (2008) From Innovation to Exporting or Vice Versa? Causal Link between Innovation Activity and Exporting in Slovenian Microdata, Licos Discussion Paper Series 204.

DE BEULE, F. and VAN BEVEREN, I. (2009) Belgium's Diamond of Competitiveness. A Comparison between Foreign and Domestic Companies. In Van Den Bulcke D., Verbeke A. and Yuan W. (Eds) Handbook On Small Nations In The Global Economy: The Contribution of Multinational Enterprises to National Economic Success. London: 
Edward Elgar.

DE BEULE F., VAN DEN BULCKE D. and XU L. (2005) Multinational subsidiaries and manufacturing clusters in Guangdong, China, in GIULIANI E., RABELLOTTI R. and VAN DIJK M. P. (Eds) Clusters Facing Competition: The Importance of External Linkages, pp. 107-34. Ashgate Publishing, Hampshire.

DUGUET, E. (2006) Innovation Height, Spillovers and Tfp Growth at the Firm Level: Evidence from French Manufacturing, Economics of Innovation and New Technology 15, 415 442.

DUNNING J. H. (1998) Globalization, technological change and spatial organisation of economic activities, in CHANDLER A. D., HAGSTROM P. and SÖLVELL Ö. (Eds) The Dynamic Firm: The Role of Technology, Strategy, Organization and Regions. Oxford University Press, Oxford.

EUROPEAN CLUSTER OBSERVATORY (2010) Cluster Methodology. http://www.clusterobservatory.eu/.

EUROSTAT (2008) Sector classification according to technology intensity and Knowledge intensity. Eurostat, Luxembourg.

EUROSTAT (2009) Structural Business Statistics Database. Eurostat, Luxembourg.

FELDMAN, M.P. (1999) The new economics of innovation, spillovers and agglomeration: A review of empirical studies, Economics of Innovation and New Technology 8, 5-25.

GRIFFITH, R., E. HUERGO, J. MAIRESSE, and B. PETERS (2006) Innovation and Productivity across Four European Countries, Oxford Review of Economic Policy 22, 483-498.

HENDERSON, J.V. (1994) Externalities and industrial development, NBER Working Paper 4730.

HENRY N. and PINCH S. (2006) Knowledge and clusters, in PITELIS C., SUGDEN R. and WILSON J. R. (Eds) Clusters and Globalisation: The Development of Urban and Regional Economies, pp. 114-32. Edgar Elgar Publishing, Cheltenham.

HIRSCH-KREINSEN, H., JACOBSON, D., LAESTADUIS, S. and SMITH, K. (2003) LowTech Industries and the Knowledge Economy: State of the Art and Research Challenges, STEP Report 16. Pilot Project. http://www.step.no/reports/Y2003/1603.pdf

HIRSCH-KREINSEN, H. (2008a) 'Low-tech' innovations, Industry and Innovation, Vol.15, no.1, 19-43.

HIRSCH-KREINSEN, H. (2008b) 'Low-technology': A forgotten sector in innovation policy. Journal of Technology Management and Innovation, Vol.3, no.3, 11-20.

JAFFE A. B. (1986) Technological opportunity, spillovers of R\&D: Evidence from firms' patents, profits and market value, American Economic Review 76, 984-1001.

JAFFE A. B., TRAJTENBERG M. and HENDERSON R. (1993) Geographical localization of knowledge spillovers as evidenced by patent citations, Quarterly Journal of Economics 108, 577-98.

KRUGMAN P. (1991) Geography and Trade. MIT Press, Cambridge, Massachussets.

MAIRESSE J. and MOHNEN P. (2002) Accounting for innovation and measuring innovativeness: An illustrative framework and an application, American Economic Review 92, 226-30.

MALMBERG A., SOLVELL O. and ZANDER I. (1996) Spatial clustering, local accumulation of knowledge and firm competitiveness, Geografiska Annaler. Series B, Human Geography 78, 85-97. 
MARKUSEN A. (1994) Studying regions by studying firms, Professional Geographer 46, 47790.

MARKUSEN A. (1996) Sticky places in slippery space: A typology of industrial districts, Economic Geography 72, 293-313.

MARSHALL A. (1890) Principles of Economics: An Introductory Volume. Macmillan, London.

MASKELL P. (2001) Knowledge creation and diffusion in geographic clusters, International Journal of Innovation Management 5, 213.

NSSO (2009) National Social Security Database. National Social Security Office, Brussels.

PORTER M. E. (1998) Clusters and the new economics of competition, Harvard Business Review 76, 77-90.

SAXENIAN A. (1990) Regional networks and the resurgence of Silicon Valley, California Management Review 33, 89-112.

SMITH, K. (2005) Measuring Innovation, in The Oxford Handbook of Innovation, (Eds) FAGERBERG J., D. C. MOWERY, and R. R. NELSON, pp. 148-77. Oxford: Oxford University Press.

STORPER M. (1995) Regional technology coalitions an essential dimension of national technology policy, Research Policy 24, 895-911.

SWAN, P. (1993) Can high-technology services prosper if high technology manufacturing doesn't?, Working Paper 143, Centre for Business Strategy, London Business School.

SWANN, G.M.P.; PREVEZER, M.; STOUT, D.(1998) The Dynamics of Industrial Clusters: International Comparisons in Computing and Biotechnology, Oxford, Oxford University Press.

TALLMAN S., JENKINS M., HENRY N. and PINCH S. (2004) Knowledge, clusters and competitive advantage, Academy of Management Review 29, 258-71.

TEIRLINCK P. (2005) Report CIS 4, Belgian Science Policy.

VAN BEVEREN, I., and H. VANDENBUSSCHE (2010) Product and Process Innovation and Firms' Decision to Export, Journal of Economic Policy Reform 13, 3-24.

VON TUNZELMANN, N. and ACHA, V. (2005) Innovation in 'low-tech' industries, in FAGERBERG, J., MOWERY, D. and NELSON, R.R. (eds.) The Oxford Handbook of Innovation, pp. 407-432. Oxford University Press.

VON ZEDTWITZ M. and HEIMANN P. (2006) Innovation in clusters and the liability of foreignness of international R\&D, in CARAYANNIS E. G. and CAMPBELL D. F. J. (Eds) Knowledge Creation, Diffusion, and Use in Innovation Networks and Knowledge Clusters: A Comparative Systems Approach across the United States, Europe and Asia, pp. 101-23. Greenwood Publishing Group. 


\begin{tabular}{|c|c|c|c|c|c|}
\hline \multicolumn{6}{|c|}{ Appendix Table A.1. Sector Classification According to Technology Intensity and Knowledge Intensity } \\
\hline \multicolumn{3}{|c|}{ Manufacturing } & \multicolumn{3}{|r|}{ Services } \\
\hline Sector & NACE & Description & Sector & $N A C E$ & Description \\
\hline \multirow{5}{*}{$\begin{array}{l}\text { High technology } \\
\text { manufacturing }\end{array}$} & 244 & Pharmaceuticals & \multirow{5}{*}{$\begin{array}{l}\text { High technology } \\
\text { Knowledge- } \\
\text { intensive } \\
\text { services }\end{array}$} & 64 & Post and telecommunications \\
\hline & 30 & Office machinery - computers & & 72 & Computer and related activities \\
\hline & 32 & Radio, TV, communication equipment & & 73 & Research and development \\
\hline & 33 & Medical, precision, optical instruments & & & \\
\hline & 353 & Aircraft - spacecraft & & & \\
\hline \multirow{5}{*}{$\begin{array}{l}\text { Medium high } \\
\text { technology } \\
\text { manufacturing }\end{array}$} & 24 & Chemicals, excl. pharmaceuticals & \multirow{14}{*}{$\begin{array}{l}\text { Low technology } \\
\text { Less knowledge } \\
\text { intensive services }\end{array}$} & 50 & Wholesale/retail trade of motor vehicles \\
\hline & 29 & Machinery and equipment & & 51 & Wholesale trade \\
\hline & 31 & Electrical machinery & & 52 & Retail trade \\
\hline & 34 & Motor vehicles & & 55 & Hotels and restaurants \\
\hline & 35 & $\begin{array}{l}\text { Other transport equipment (excl. } 351 \& \\
\text { 353) }\end{array}$ & & 60 & Land transport \\
\hline \multirow{6}{*}{$\begin{array}{l}\text { Medium low } \\
\text { technology } \\
\text { manufacturing }\end{array}$} & 23 & Coke, refined petroleum products & & 61 & Water transport \\
\hline & 25 & Rubber and plastic & & 62 & Air transport \\
\hline & 26 & Nonmetallic mineral products & & 63 & Supporting transport activities \\
\hline & 27 & Basic metals & & 65 & Financial intermediation \\
\hline & 28 & Fabricated metal products & & 66 & Insurance and pension funding \\
\hline & 351 & Building/repairing of ships and boats & & 67 & Ancilliary financial activities \\
\hline \multirow{10}{*}{$\begin{array}{l}\text { Low technology } \\
\text { manufacturing }\end{array}$} & 15 & Food and beverages & & 70 & Real estate activities \\
\hline & 16 & Tobacco & & 71 & Renting activities \\
\hline & 17 & Textiles & & 74 & Other business activities \\
\hline & 18 & Clothing & & & \\
\hline & 19 & Leather (products) & & & \\
\hline & 20 & Wood (products) & & & \\
\hline & 21 & Pulp, paper (products) & & & \\
\hline & 22 & Publishing and printing & & & \\
\hline & 36 & Furniture & & & \\
\hline & 37 & Recycling & & & \\
\hline & & Source: 1 & stat (2008) & & \\
\hline
\end{tabular}




\section{Appendix B: Definitions of variables}

The Community Innovation Survey (CIS4) collects information on innovations at the firm level for the period $2002-2004$. Although the survey is organized by the EU, data are collected by national authorities. For Belgium BELSPO is responsible for the data collection. Apart from innovation-related information, the survey also records general information on the firm's activities, such as the level of employment, turnover, export intensity etc.

\section{Innovation indicators}

\section{Product innovation}

During the years 2002-2004, did your enterprise introduce new or significantly improved goods (services)?

\section{Share of new products in turnover}

Please give percentage of your total turnover in 2004 from: goods and service innovations introduced during 2002-2004 that were new to your market, or only new to the firm ${ }^{6}$.

\section{Expenditures on $R \& D$}

Please estimate the amount of expenditure for each of your intramural R\&D activities in 2004 only.

\section{Funding}

During the years 2002-2004, did your enterprise receive any public financial support for innovation activities from the following levels of government (regional, national or EUlevel)? Include financial support via tax credits or deductions, grants, subsidised loans, and loan guarantees. Exclude research and other innovation activities conducted entirely for the public sector under contract.

\section{Basic economic information on the enterprise}

\section{Employment}

What was your enterprise's total number of employees in 2002 and 2004 ?

\section{Turnover}

\footnotetext{
${ }^{6}$ The share of new products in turnover is recorded separately for product innovations new to the market and new to the firm. To obtain the total share of new products in total sales, we have summed both categories.
} 
What was your enterprise's total turnover in 2002 and 2004?

\section{Foreign ownership}

Is your enterprise part of an enterprise group? In which country is the head office of your group located?

\section{Export intensity}

How high was your export intensity in 2004 (percentage of sales, between 0 and 100) 


\begin{tabular}{|l|c|c|c|}
\hline \multicolumn{3}{|c|}{ Table 1: Summary statistics of key variables by geographical region } \\
\hline Variables & Brussels & $\begin{array}{c}\text { Flemish } \\
\text { region }\end{array}$ & $\begin{array}{c}\text { Walloon } \\
\text { region }\end{array}$ \\
\hline Number of firms & 714 & 1,525 & 1,007 \\
\hline R\&D intensity (Internal R\&D/sales) & 0.012 & 0.017 & 0.017 \\
Product Innovation (d) & 0.221 & 0.368 & 0.243 \\
\hline Share of new products in turnover & 0.058 & 0.086 & 0.052 \\
\hline Funding (d) (1) & 0.070 & 0.147 & 0.138 \\
\hline Firm size (log employment) & 3.575 & 3.815 & 3.813 \\
\hline $\begin{array}{l}\text { Export intensity } \\
\text { Foreign ownership (d) }\end{array}$ & 0.136 & 0.269 & 0.258 \\
\hline Employment concentration (2) & 0.338 & 0.243 & 0.242 \\
\hline $\begin{array}{l}\text { Values reported refer to sample means, except in the first row, where the number of } \\
\text { observations is reported. (1)The funding dummy indicates whether a firm has received } \\
\text { regional, national or EU-level innovation subsidies. (2) Employment concentration is } \\
\text { defined as a continuous measure, defined at the sector level and normalized by } \\
\text { employment concentration of the sector in the EU-15. Variables are defined in } \\
\text { Appendix A of the paper. }\end{array}$ \\
\hline
\end{tabular}




\begin{tabular}{|c|c|c|c|c|}
\hline \multicolumn{5}{|c|}{ Table 2: Regression results Product innovation } \\
\hline & $\mathrm{I}$ & II & III & IV \\
\hline Employment Concentration & & $0.007 * *$ & $0.007 * *$ & $0.007 * *$ \\
\hline (Cluster measure, 2004) & & {$[2.364]$} & {$[2.373]$} & [2.412] \\
\hline R\&D intensity & $2.558 * *$ & $2.557 * *$ & $2.232 * *$ & $1.211^{*}$ \\
\hline (R\&D/sales, 2004) & [2.166] & {$[2.163]$} & [1.990] & [1.737] \\
\hline Firm size & $0.079 * * *$ & $0.078 * * *$ & $0.063 * * *$ & $0.052 * * *$ \\
\hline (log of employment, fte, 2004) & [11.145] & [11.018] & [8.397] & [6.629] \\
\hline Export intensity & & & $0.202 * * *$ & $0.175^{* * *}$ \\
\hline (Export sales/total sales, 2004) & & & [7.342] & [6.232] \\
\hline Foreign ownership & & & 0.030 & $0.060 * *$ \\
\hline (Dummy, 2004) & & & [1.294] & [2.484] \\
\hline Funding & & & & $0.434 * * *$ \\
\hline (Dummy, 2004) & & & & [14.377] \\
\hline Brussels region & $-0.070 * * *$ & $-0.072 * * *$ & $-0.066 * * *$ & $-0.064 * * *$ \\
\hline (Dummy, 2004) & {$[-3.232]$} & {$[-3.357]$} & {$[-3.012]$} & {$[-2.876]$} \\
\hline Walloon region & $-0.111 * * *$ & $-0.108 * * *$ & $-0.112 * * *$ & $-0.127 * * *$ \\
\hline (Dummy, 2004) & {$[-6.154]$} & {$[-5.960]$} & {$[-6.153]$} & {$[-6.853]$} \\
\hline Number of observations & 3,246 & 3,246 & 3,246 & 3,246 \\
\hline Psuedo R-square & 0.159 & 0.160 & 0.176 & 0.224 \\
\hline \multicolumn{5}{|c|}{$\begin{array}{l}\text { Notes: All regressions include sector dummies, in addition to the region dummies. The } \\
\text { dependent variable is a dummy, indicating whether the firm has introduced a product } \\
\text { innovation (new to the firm or the market) between } 2002 \text { and } 2004 \text {. Values are marginal } \\
\text { effects [t-values], evaluated at the mean of the independent variables and referring to the } \\
\text { impact on the probability to innovate. For dummy variables (d), marginal effects refer to } \\
\text { discrete change from } 0 \text { to } 1 \text {. Significance levels: } * * * p<0.01 ; * * p<0.05 ; * p<0.10 \text {. }\end{array}$} \\
\hline
\end{tabular}




\begin{tabular}{|c|c|c|c|c|}
\hline \multicolumn{5}{|c|}{ Table 3: Regression results Product renewal } \\
\hline Independent variables & $\mathrm{I}$ & II & III & IV \\
\hline Employment Concentration & & $0.002 * *$ & $0.002 * *$ & $0.002 * *$ \\
\hline (Cluster measure, 2004) & & [2.224] & [2.277] & [2.233] \\
\hline R\&D intensity & $0.286^{* * *}$ & $0.283^{* * *}$ & $0.254 * * *$ & $0.165^{* * *}$ \\
\hline (R\&D/sales, 2004) & {$[8.002]$} & [7.918] & {$[7.408]$} & [5.112] \\
\hline Firm size & $0.016^{* * * *}$ & $0.016^{* * * *}$ & $0.012 * * *$ & $0.008 * * *$ \\
\hline (log of employment, fte, 2004) & [9.653] & [9.447] & [6.541] & [4.494] \\
\hline Export intensity & & & $0.050 * * *$ & $0.036 * * *$ \\
\hline (Export sales/total sales, 2004) & & & {$[7.068]$} & {$[5.380]$} \\
\hline Foreign ownership & & & 0.007 & $0.014 * *$ \\
\hline (Dummy, 2004) & & & {$[1.210]$} & {$[2.576]$} \\
\hline Funding & & & & $0.105 * * *$ \\
\hline (Dummy, 2004) & & & & {$[9.375]$} \\
\hline Brussels region & $-0.010 *$ & $-0.011 *$ & -0.008 & -0.006 \\
\hline (Dummy, 2004) & {$[-1.683]$} & {$[-1.795]$} & {$[-1.347]$} & {$[-1.054]$} \\
\hline Walloon region & $-0.027 * * *$ & $-0.026 * * *$ & $-0.027 * * *$ & $-0.027 * * *$ \\
\hline (Dummy, 2004) & {$[-5.951]$} & {$[-5.753]$} & {$[-5.928]$} & {$[-6.219]$} \\
\hline Number of observations & 3,246 & 3,246 & 3,246 & 3,246 \\
\hline Psuedo R-square & 0.156 & 0.157 & 0.174 & 0.221 \\
\hline \multicolumn{5}{|c|}{$\begin{array}{l}\text { Notes: All regressions include sector dummies, in addition to region dummies. The } \\
\text { dependent variable is the share of new products in total sales, where new products are } \\
\text { new to the market or new to the firm. Values are marginal effects [t-values], evaluated } \\
\text { at the mean of the independent variables and referring to the impact on innovative sales } \\
\text { intensity, conditional on positive innovative sales. For dummy variables (d), marginal } \\
\text { effects refer to discrete change from } 0 \text { to } 1 \text {. Significance levels: } * * * p<0.01 ; * * p< \\
0.05 ; * \mathrm{p}<0.10 .\end{array}$} \\
\hline
\end{tabular}




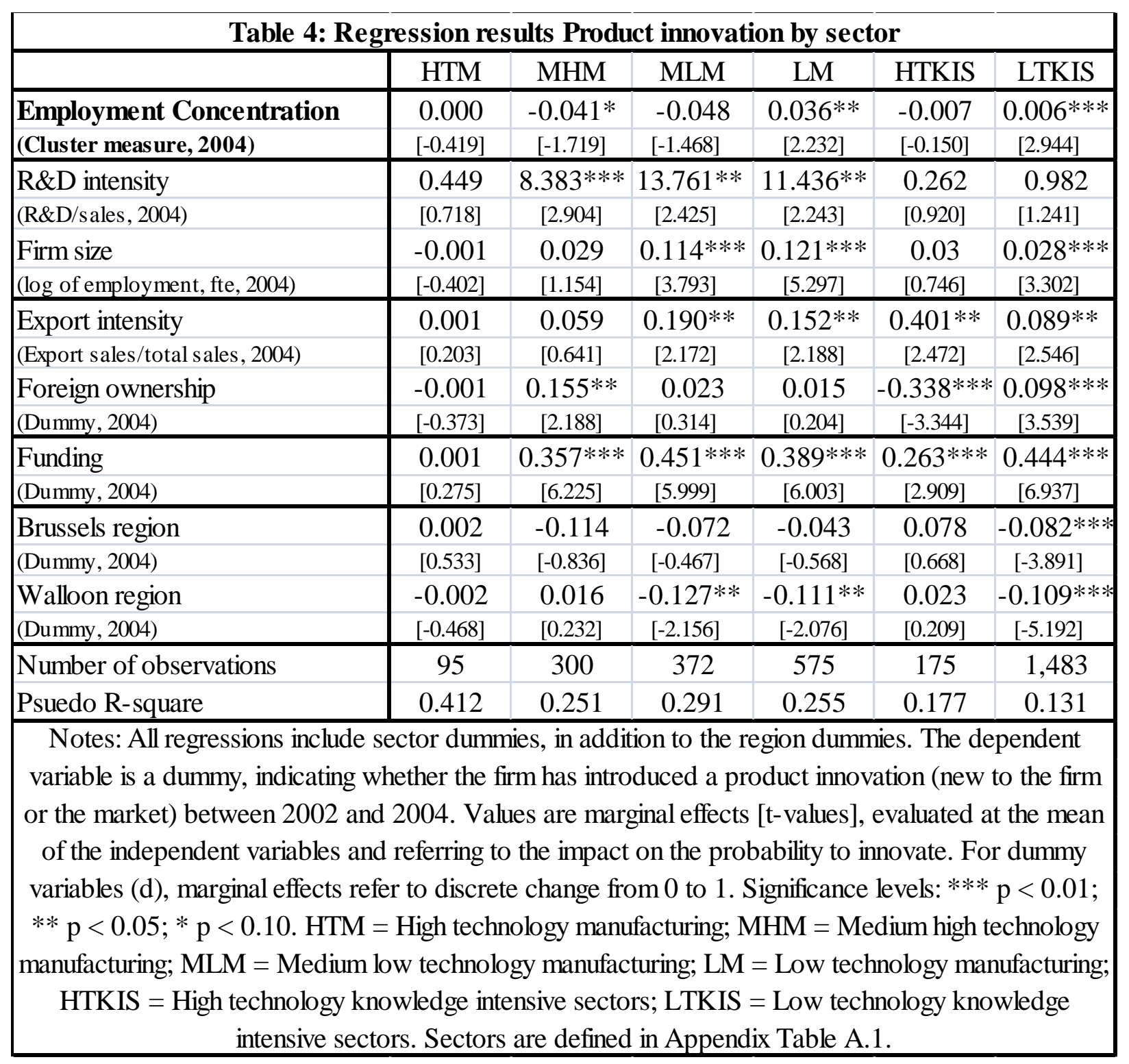




\begin{tabular}{|c|c|c|c|c|c|c|}
\hline \multicolumn{7}{|c|}{ Table 5: Regression results Product renewal by sector } \\
\hline & HTM & & MLM & LM & HTKIS & LTKIS \\
\hline Employment Concentration & -0.013 & $-0.025 * * *$ & -0.008 & $0.007 *$ & -0.008 & $0.002 * * *$ \\
\hline (Cluster measure, 2004) & {$[-0.802]$} & {$[-2.997]$} & {$[-1.299]$} & [1.700] & {$[-0.430]$} & [3.101] \\
\hline R\&D intensity & $0.867 * *$ & $0.618^{* *}$ & $0.810^{* * * *}$ & $0.531 * * *$ & 0.190 & $0.133^{* * *}$ \\
\hline (R\&D/sales, 2004) & {$[2.385]$} & [2.481] & [2.951] & [2.971] & [1.605] & [3.340] \\
\hline Firm size & $0.034^{*}$ & 0.015 & $0.010^{* * *}$ & $0.015^{* * *}$ & 0.003 & $0.005^{* *}$ \\
\hline (log of employment, fte, 2004) & {$[1.750]$} & [1.465] & {$[2.179]$} & [3.698] & {$[0.232]$} & {$[2.180]$} \\
\hline Export intensity & 6 & 34 & $0.054 * * *$ & $* *$ & $0.094 *$ & $7 *$ \\
\hline (Export sales/total sales & {$[-0.100]$} & [1.020] & {$[3.145]$} & {$[2.238]$} & [1.744] & [1.863] \\
\hline Foreign ownership & $-0.089^{*}$ & $0.070 * * *$ & 0.004 & -0.004 & $-0.109 * * *$ & $0.030 * * *$ \\
\hline (Dummy, 2004) & {$[-1.863]$} & {$[2.743]$} & [0.295] & {$[-0.333]$} & {$[-3.045]$} & [3.785] \\
\hline Funding & $0.083^{*}$ & $0.102 * * *$ & $0.094 * * *$ & $0.093 * * *$ & $0.128 * * *$ & $0.159 * * *$ \\
\hline (Dummy, 2004) & {$[1.766]$} & {$[4.233]$} & {$[3.474]$} & {$[4.744]$} & {$[2.768]$} & [4.819] \\
\hline Brussels region & 0.014 & $-0.075^{* * *}$ & -0.009 & 0.002 & 0.056 & $-0.011^{*}$ \\
\hline (Dummy, 2004) & {$[0.164]$} & {$[-3.020]$} & {$[-0.264]$} & {$[0.095]$} & {$[1.054]$} & {$[-1.892]$} \\
\hline Walloon region & $-0.092 * *$ & -0.026 & $-0.032 * *$ & $-0.018^{*}$ & 0.001 & $-0.021 * * *$ \\
\hline (Dummy, 2004) & {$[-2.349]$} & {$[-1.115]$} & {$[-2.578]$} & {$[-1.739]$} & [0.031] & {$[-3.647]$} \\
\hline Number of obs & 95 & 300 & 372 & 575 & 175 & 1,483 \\
\hline Psuedo R-square & 0.363 & 0.213 & 0.238 & 0.211 & 0.2 & 0.131 \\
\hline \multicolumn{7}{|c|}{$\begin{array}{l}\text { Notes: All regressions include sector dummies, in addition to region dummies. The dependent variable is the } \\
\text { share of new products in total sales, where new products are new to the market or new to the firm. Values } \\
\text { are marginal effects [t-values], evaluated at the mean of the independent variables and referring to the } \\
\text { impact on innovative sales intensity, conditional on positive innovative sales. For dummy variables (d), } \\
\text { marginal effects refer to discrete change from } 0 \text { to } 1 . \text { Significance levels: } * * * p<0.01 ; * * p<0.05 ; * \mathrm{p}< \\
0.10 . \mathrm{HTM}=\text { High technology manufacturing; MHM = Medium high technology manufacturing; MLM = } \\
\text { Medium low technology manufacturing; LM = Low technology manufacturing; HTKIS = High technology } \\
\text { knowledge intensive sectors; LTKIS = Low technology knowledge intensive sectors. Sectors are defined in } \\
\text { Appendix Table A.1. }\end{array}$} \\
\hline
\end{tabular}

